\title{
Application of ion mobility spectrometry for the detection of human urine
}

\author{
Joanna Rudnicka $\cdot$ Pawel Mochalski • \\ Agapios Agapiou • Milt Statheropoulos • \\ Anton Amann • Bogusław Buszewski
}

Received: 22 July 2010 /Revised: 18 August 2010 /Accepted: 18 August 2010 /Published online: 5 September 2010

(C) The Author(s) 2010. This article is published with open access at Springerlink.com

\begin{abstract}
The aim of the present study was to evaluate the suitability of ion mobility spectrometry (IMS) for the detection of human urine as an indication of human presence during urban search and rescue operations in collapsed buildings. To this end, IMS with a radioactive ionization source and a multicapillary column was used to detect volatile organic compounds (VOCs) emitted from human urine. A study involving a group of 30 healthy volunteers resulted in the selection of seven volatile species, namely acetone, propanal, 3-methyl-2-butanone, 2-methylpropanal, 4-heptanone, 2-heptanone and octanal,
\end{abstract}

J. Rudnicka $\cdot$ B. Buszewski $(\square)$

Department of Environmental Chemistry and Bioanalytics,

Faculty of Chemistry, Nicolaus Copernicus University,

7 Gagarin St,

87100 Toruń, Poland

e-mail: bbusz@chem.uni.torun.pl

J. Rudnicka $\cdot$ P. Mochalski $\cdot$ A. Amann

Breath Research Institute of the Austrian Academy of Sciences,

Dammstrasse 22,

6850 Dornbirn, Austria

P. Mochalski

Institute of Nuclear Physics PAN,

Radzikowskiego 152,

31342 Kraków, Poland

A. Agapiou • M. Statheropoulos

School of Chemical Engineering, National Technical University of Athens (NTUA),

Sector I, 9 Iroon Polytechniou Street,

15773 Athens, Greece

\author{
A. Amann \\ Department of Anesthesiology and General Intensive Care, \\ Innsbruck Medical University, \\ Anichstrasse 35, \\ 6020 Innsbruck, Austria
}

which were detected in all samples. Additionally, a preliminary study on the permeation of urine volatiles through the materials surrounding the voids of collapsed buildings was performed. In this study, quartz sand was used as a representative imitating material. Four compounds, namely 3-methyl-2-butanone, octanal, acetone and 2-heptanone, were found to permeate through the sand layers during all experiments. Moreover, their permeation times were the shortest. Although IMS can be considered as a potential technique suitable for the detection, localization and monitoring of VOCs evolved from human urine, further investigation is necessary prior to selecting field chemical methods for the early location of trapped victims.

Keywords Ion mobility spectrometry - Volatile organic compounds - Urine markers - Location of trapped victims . Urban search and rescue operations

\section{Introduction}

The early location of victims trapped in collapsed buildings is of particular importance for rescue teams after natural or man-made disasters. Currently, the use of canines is the method of choice in urban search and rescue operations [1]. Canines exhibit excellent scenting skills and are able to search relatively large areas in a short period of time. However, search dogs have a number of limitations: the information they provide must be correctly interpreted, their training is time-consuming and expensive and their working time is relatively short. Moreover, at the disaster scene canines can become temperamental, stressed and even frustrated when scenting dead victims [2]. Therefore, a demand exists for novel technical search tools which could complement or even replace their work. 
In this context, knowledge of the human scent profile and its interaction with the disaster environment is crucial. Volatile markers of trapped victims can be released from different biological fluids (urine, blood, sweat) or tissues (skin or lungs). Their emission can be influenced by the medical status of the victim prior to and after collapse and the time for which they have been trapped. The resulting human scent may be modified by numerous interactions with the environment. In addition, the concentrations of species specific for human scent are extremely low, thus making their identification a challenging task.

Urine can be an important source of volatile markers of trapped persons. However, relatively few studies have investigated the profile of volatile organic compounds (VOCs) released spontaneously by non-modified human urine [3-5]. Volatile species emitted by human urine belong to numerous classes, such as hydrocarbons, aldehydes, ketones, furans, pyrroles, terpenes, sulfur-containing compounds and heterocyclic compounds. In a recent study, a set of 33 volatile markers that are omnipresent in human urine released spontaneously at human body temperature were detected and identified using solid-phase microextraction (SPME) and gas chromatography coupled with mass spectrometry (GC-MS) [3]. This set of species can be considered as an initial library to be used for detection of human urine.

For the detection, localization and monitoring of these VOCs in the field, portable, highly sensitive and selective instruments providing a relatively short response time need to be used. Ion mobility spectrometry (IMS) seems to meet these requirements. Currently, the IMS technique is used in biological analyses [6, 7], medical diagnostics [8-12] and food quality measurements $[13,14]$. The IMS devices can be quite small and held in the hand. Portable IMS instruments are commonly used for the detection of chemical warfare agents and illegal drugs [15-17].

IMS consists of an ionization chamber, an ion-molecule injection shutter, an ion drift tube and an ion collector (Faraday plate) [8]. Different methods are used to ionize gas; usually radioactive sources such as ${ }^{63} \mathrm{Ni}$ are employed $[8,10]$. An alternative way is the UV light $[18,19]$. A carrier gas, usually air or nitrogen, introduces analyte molecules into the ion source where they undergo ionization. Afterwards, the ions are injected by opening an ion shutter into the drift region and separated according to ion mobility differences [8].

IMS is often coupled with standard gas chromatographic columns [18] or multicapillary columns (MCC) [8] for enhancing the separation of analysis. MCC characterize comparatively high flow rate and high sample capacity in comparison to single narrow columns [8].

The main goals of this study were firstly the evaluation of the suitability of the IMS technique for the detection of human urine emitted VOCs with or without permeation through quartz sand imitating trapment materials and secondly the selection of the most promising volatile urine markers which could be detected with this technique.

\section{Experimental}

Instrumentation

An ion mobility spectrometer (ISAS-Institute for Analytical Sciences, Dortmund, Germany) with a radioactive ionization source $\left({ }^{63} \mathrm{Ni}\right)$ was applied for urine analysis. The principal parameters for the IMS are summarized in Table 1.

The device was equipped with a 20 -cm-long polar multicapillary column (MCC; OV-5, Sibertech, Novosibirsk, Russia). The MCC consists of approximately 1,200 capillaries, with an inner diameter of $40 \mu \mathrm{m}$ and a film thickness of $0.2 \mu \mathrm{m}$ coupled to the ${ }^{63} \mathrm{Ni}-\mathrm{IMS}$ system. The flow rate of the carrier gas was $100 \mathrm{~mL} / \mathrm{min}$. Separation of analytes was performed isothermally at $30{ }^{\circ} \mathrm{C}$. Gas samples were injected using a $10-\mathrm{mL}$ sample loop installed on the six-way valve.

Each final ion mobility spectrum was an average of five measurements recorded for $100 \mathrm{~ms}$ with a frequency of 25,000 samples per second. Such a setting provided two ion mobility spectra per second of analysis. Further details on the IMS system applied are given elsewhere [20-22].

\section{Chemicals and standards}

Identification parameters (drift times and retention times) were obtained on the basis of calibration mixtures prepared from pure compounds. An effort was made to prepare a separate standard for each compound. Primary standards

Table 1 Parameters for multicapillary column $(M C C)$ ion mobility spectrometry $(I M S)$

\begin{tabular}{ll}
\hline Parameter & MCC $-{ }^{63} \mathrm{Ni}-\mathrm{IMS}$ \\
\hline Ionization source & ${ }^{63} \mathrm{Ni}(550 \mathrm{MBq})$ \\
Length of the drift tube & $120 \mathrm{~mm}$ \\
Electrical field strength & $333 \mathrm{~V} / \mathrm{cm}$ \\
Drift voltage & $4 \mathrm{kV}$ \\
Shutter opening time & $300 \mu \mathrm{s}$ \\
Drift gas & $\mathrm{N}_{2}(99.9999 \%)$ \\
Drift gas flow & $100 \mathrm{~mL} / \mathrm{min}$ \\
Temperature (IMS) & $23{ }^{\circ} \mathrm{C}$ (ambient) \\
Pressure & $950 \mathrm{hPa}$ (ambient) \\
Stationary phase of the MCC & $\mathrm{OV}-5$ (polar) \\
Temperature (MCC) & $30{ }^{\circ} \mathrm{C}$ \\
\hline
\end{tabular}


were prepared in a 1-L glass gas bulb (Supelco, Canada). Prior to use, the bulb was thoroughly cleaned with methanol and dried at $70{ }^{\circ} \mathrm{C}$ for at least $12 \mathrm{~h}$. Afterwards, it was purged with pure nitrogen (99.9999\%) for $20 \mathrm{~min}$. Then, the bulb was evacuated using a vacuum pump and approximately $1 \mu \mathrm{L}$ of pure compound was injected through a rubber septum. After the evaporation of the compound, the bulb was balanced with nitrogen. The final standard was prepared by transferring an appropriate volume of primary standard into a 3-L Tedlar bag (SKC, USA) filled with $1 \mathrm{~L}$ of pure nitrogen. The final concentrations of the analytes under study in secondary standards ranged from 20 to $80 \mathrm{ppb}$. A number of standards were purchased from Sigma-Aldrich (Vienna, Austria); 2heptanone (98\%), 2-methyl-1-propanal (99\%), 3-hexanone (98\%), 3-methyl-2-pentanone (99\%), dimethyl disulfide (99\%), ethyl acetate $(99.9 \%)$, furan $(99 \%)$, hexanal (98\%), methyl acetate $(99.5 \%)$, pentanal $(97 \%)$ and toluene (99.8\%). 2-Butanone (99.5\%), 2-methylbutanal (99\%), 2pentanone (99\%), 3-methyl-2-butanone (98.5\%), 4-methyl2-pentanone (99.7\%), dimethyl sulfide (99\%), dimethyl sulfone (98\%) and isoprene $(99.5 \%)$ were obtained from Fluka (Sigma-Aldrich, Vienna, Austria). Moreover, 2methyl-2-butenal (96\%), 3-penten-2-one (better than 70\%) and dimethyl trisulfide (98\%) were provided by SAFC (Vienna, Austria), 3-methylfuran (98\%), 4-heptanone (98\%) and propanal (97\%) were provided by Acros Organics (Fisher Scientific, Vienna, Austria), acetone $(99.5 \%)$ by was provided by Merck (Merck, Vienna, Austria) and 1,2,3-trimethylbenzene (98\%) was purchased from ChemSampCo (Vienna, Austria).

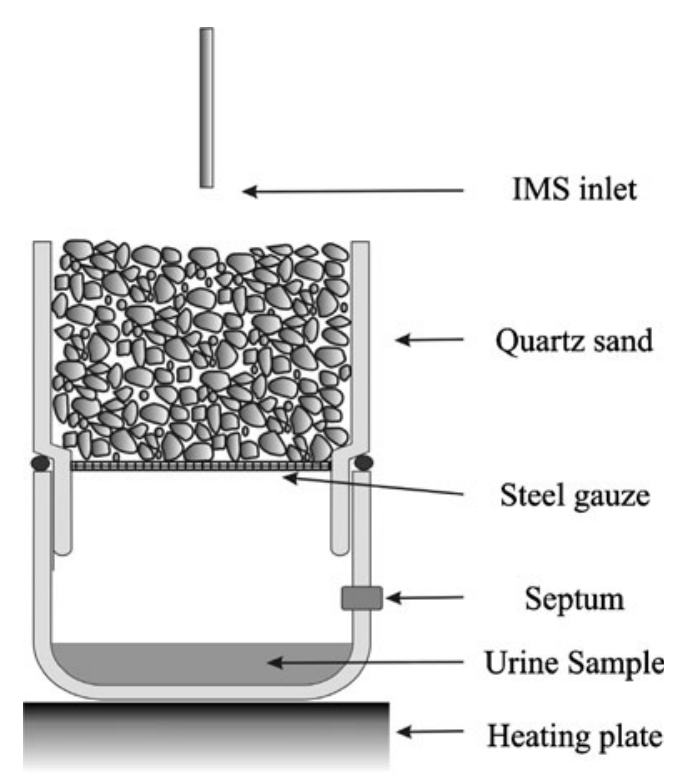

Fig. 1 The filling chamber. IMS ion mobility spectrometer
Table 2 Demographic data of volunteers

\begin{tabular}{lll}
\hline & Male & Female \\
\hline Number of volunteers & 20 & 10 \\
Mean age (range) (years) & $34(22-53)$ & $27(23-29)$ \\
Number of smokers & 2 & 2 \\
Urine type & 12 & 9 \\
Morning urine & 7 & 2 \\
Spontaneous urine & & \\
\hline
\end{tabular}

\section{Urine sampling}

The urine collection was approved by the Ethics Commission of Innsbruck Medical University. Volunteers' urine was collected in three $10-\mathrm{mL}$ plastic urine monovette vessels (Sarstedt, Germany), immediately after the volunteers had urinated. Prior to their use, urine monovettes were rinsed for $4 \mathrm{~h}$ with purified air at $50{ }^{\circ} \mathrm{C}$ to reduce possible contaminant emission during transport and storage. An effort was made to limit the urine storage in the urine monovettes to $3 \mathrm{~h}$. Two types of urine were sampled: morning urine, which is expected to exhibit higher VOCs levels as it is more concentrated (particularly when the subject is dehydrated), and spontaneous urine.

\section{Detection of VOCs in the headspace of human urine}

To investigate the possible interaction (e.g. overlapping, signal suppressing) between evolved urine VOCs, a series of measurements of the urine headspace was performed. They were accomplished using 1-L glass flasks. The flasks were thoroughly cleaned prior to the experiment and flushed with pure nitrogen to remove contaminants. Afterwards, $2 \mathrm{~mL}$ of urine sample was transferred from the monovette into the flask. The temperature of the glass flask was maintained at $36-37{ }^{\circ} \mathrm{C}$ to investigate the emission of VOCs at human body temperature. After $5 \mathrm{~min}, 10 \mathrm{~mL}$ of the headspace gas was introduced into the sample loop and analysed by MCC/IMS. Each measurement was repeated three times.

Detection of VOCs permeating through debris material

In the ruins of collapsed buildings, volatiles are carried out by air currents and spread as plumes throughout the rubble; these plumes are either constant or transient. Consequently, interactions of VOCs with the debris materials (e.g. dust, wood, plastic, glass) are expected to significantly modify the urine scent. In this context, the permeative properties of urine markers have a crucial influence on the success of the search and rescue operation. A preliminary study on this aspect was done with a filling chamber as presented in 
Table 3 Identification parameters of ubiquitous volatile organic compounds (VOCs) in human urine with their proton affinities [23]

\begin{tabular}{|c|c|c|c|c|c|}
\hline Name & CAS no. & $\begin{array}{l}\text { Proton affinity } \\
(\mathrm{kJ} / \mathrm{mol})\end{array}$ & Peak & $\begin{array}{l}\text { Retention } \\
\text { time }(\mathrm{s})\end{array}$ & $\begin{array}{l}\text { Reduced ion } \\
\text { mobility }\left(\mathrm{cm}^{2} / \mathrm{Vs}\right)\end{array}$ \\
\hline 1,2,3-Trimethylbenzene & $526-73-8$ & no data & I & 41.4 & 1.77 \\
\hline \multirow[t]{2}{*}{ 2-Butanone } & $78-93-3$ & 827.3 & I & 5.5 & 1.87 \\
\hline & & & II & 5.6 & 1.61 \\
\hline \multirow[t]{3}{*}{ 2-Heptanone } & $110-43-0$ & No data & I & 19.1 & 1.57 \\
\hline & & & II & 19.1 & 1.47 \\
\hline & & & III & 19.1 & 1.23 \\
\hline \multirow[t]{2}{*}{ 2-Methyl-1-propanal } & $78-84-2$ & 797.3 & I & 6 & 1.74 \\
\hline & & & II & 6 & 1.66 \\
\hline \multirow[t]{2}{*}{ 2-Methyl-2-butenal } & $1115-11-3$ & 843.7 & I & 8 & 1.81 \\
\hline & & & II & 8 & 1.48 \\
\hline 2-Methylbutanal & $96-17-3$ & No data & I & 7 & 1.66 \\
\hline \multirow[t]{3}{*}{ 2-Pentanone } & $107-87-9$ & 832.7 & I & 8 & 1.77 \\
\hline & & & II & 8 & 1.58 \\
\hline & & & III & 11.3 & 1.46 \\
\hline \multirow[t]{3}{*}{ 3-Hexanone } & $589-38-8$ & 843.2 & I & 9 & 1.71 \\
\hline & & & II & 8 & 1.44 \\
\hline & & & III & 9 & 1.38 \\
\hline \multirow[t]{3}{*}{ 3-Methyl-2-butanone } & $563-80-4$ & 836.3 & I & 5 & 1.8 \\
\hline & & & II & 5 & 1.65 \\
\hline & & & III & 5.5 & 1.48 \\
\hline \multirow[t]{2}{*}{ 3-Methyl-2-pentanone } & $565-61-7$ & No data & I & 8.3 & 1.69 \\
\hline & & & II & 8.3 & 1.35 \\
\hline \multirow[t]{4}{*}{ 3-Methylfuran } & $930-27-8$ & 854 & I & 9 & 1.87 \\
\hline & & & II & 8.3 & 1.79 \\
\hline & & & III & 8.3 & 1.57 \\
\hline & & & IV & 8.3 & 1.45 \\
\hline \multirow[t]{3}{*}{ 3-Penten-2-one } & $625-33-2$ & 864.7 & I & 8 & 1.71 \\
\hline & & & II & 8 & 1.44 \\
\hline & & & III & 8.9 & 1.38 \\
\hline \multirow[t]{3}{*}{ 4-Heptanone } & $123-19-3$ & 845 & I & 15.6 & 1.62 \\
\hline & & & II & 18 & 1.48 \\
\hline & & & III & 14.5 & 1.27 \\
\hline \multirow[t]{3}{*}{ 4-Methyl-2-pentanone } & $108-10-1$ & No data & I & 8.9 & 1.7 \\
\hline & & & II & 6.7 & 1.55 \\
\hline & & & III & 7.8 & 1.36 \\
\hline Acetone & $67-64-1$ & 812 & I & 5.6 & 1.78 \\
\hline Allyisothiocyanate & $57-06-7$ & No data & \multicolumn{3}{|c|}{ Not measured } \\
\hline Dimethyl disulfide & $624-92-0$ & 815.3 & \multicolumn{3}{|c|}{ In RIP area } \\
\hline Dimethyl sulfide & $75-18-3$ & 830.9 & \multicolumn{3}{|c|}{ In RIP area } \\
\hline Dimethyl sulfone & $67-71-0$ & No data & \multicolumn{3}{|c|}{ In RIP area } \\
\hline Dimethyl trisulfide & $3658-80-8$ & No data & \multicolumn{3}{|c|}{ In RIP area } \\
\hline Ethyl acetate & $141-78-6$ & 835.7 & I & 6.6 & 1.49 \\
\hline Furan & $110-00-9$ & 812 & \multicolumn{3}{|c|}{ Not detected } \\
\hline \multirow[t]{2}{*}{ Hexanal } & $66-25-1$ & No data & I & 8.5 & 1.56 \\
\hline & & & II & 10 & 1.29 \\
\hline \multirow[t]{2}{*}{ Isoprene } & $78-79-5$ & 826.4 & I & 44.2 & 1.65 \\
\hline & & & II & 44.2 & 1.53 \\
\hline Isothiocyanocyclohexane & $1122-82-3$ & No data & \multicolumn{3}{|c|}{ Not measured } \\
\hline
\end{tabular}


Table 3 (continued)

\begin{tabular}{|c|c|c|c|c|c|}
\hline Name & CAS no. & $\begin{array}{l}\text { Proton affinity } \\
(\mathrm{kJ} / \mathrm{mol})\end{array}$ & Peak & $\begin{array}{l}\text { Retention } \\
\text { time (s) }\end{array}$ & $\begin{array}{l}\text { Reduced ion } \\
\text { mobility }\left(\mathrm{cm}^{2} / \mathrm{Vs}\right)\end{array}$ \\
\hline Methanethiol & $74-93-1$ & 773.4 & \multicolumn{3}{|c|}{ Not detected } \\
\hline Methyl acetate & $79-20-9$ & 821.6 & I & 6.1 & 1.68 \\
\hline$N$-Methylpyrrole & $96-54-8$ & No data & \multicolumn{3}{|c|}{ Not measured } \\
\hline \multirow[t]{3}{*}{ Octanal } & \multirow[t]{3}{*}{$124-13-0$} & \multirow[t]{3}{*}{ No data } & I & 43 & 1.4 \\
\hline & & & II & 43 & 1.35 \\
\hline & & & III & 43 & 1.11 \\
\hline \multirow[t]{2}{*}{ Pentanal } & \multirow[t]{2}{*}{$110-62-3$} & \multirow[t]{2}{*}{796.6} & I & 6.7 & 1.64 \\
\hline & & & II & 6.7 & 1.41 \\
\hline \multirow[t]{2}{*}{ Propanal } & \multirow[t]{2}{*}{$123-38-6$} & \multirow[t]{2}{*}{786} & I & 1.1 & 1.75 \\
\hline & & & II & 1.1 & 1.71 \\
\hline Pyrrole & $109-97-7$ & 875.4 & I & 45.5 & 1.21 \\
\hline Toluene & $108-88-3$ & 784 & \multicolumn{3}{|c|}{ Not detected } \\
\hline
\end{tabular}

$R I P$ reactant ion peak

Fig. 1. The chamber consists of a stainless steel cylinder with an open upper end having an internal diameter of $102 \mathrm{~mm}$ and a height of $81 \mathrm{~mm}$. Steel gauze (mesh size $1 \mathrm{~mm}$ ) divides the chamber into two parts (each $40 \mathrm{~mm}$ high). The top part was loosely packed with mimicking debris quartz sand (Euroquarz, Germany) having a bulk density of $1.6 \mathrm{~g} / \mathrm{cm}^{3}$ and a particle of density $2.65 \mathrm{~g} / \mathrm{cm}^{3}$. Three sizes of grain were tested: $0.5-1 \mathrm{~mm}, 1-2 \mathrm{~mm}$ and 4-8 $\mathrm{mm}$. In the wall of the bottom part, an additional rubber septum (Supelco, Canada) was installed. The
Table 4 VOCs identified in the headspace of human urine

\begin{tabular}{|c|c|c|c|c|c|}
\hline \multirow[t]{2}{*}{ Compound } & \multirow{2}{*}{$\begin{array}{l}\text { Peak } \\
\text { number }\end{array}$} & \multicolumn{2}{|l|}{ Male } & \multicolumn{2}{|l|}{ Female } \\
\hline & & $\begin{array}{l}\text { Morning } \\
\text { urine } \\
\text { (12 samples) }\end{array}$ & $\begin{array}{l}\text { Spontaneous } \\
\text { urine }(7 \\
\text { samples) }\end{array}$ & $\begin{array}{l}\text { Morning } \\
\text { urine ( } 9 \\
\text { samples) }\end{array}$ & $\begin{array}{l}\text { Spontaneous } \\
\text { urine }(2 \\
\text { samples })\end{array}$ \\
\hline Acetone & I & 12 & 7 & 9 & 2 \\
\hline Propanal & I & 12 & 7 & 9 & 2 \\
\hline 3-Methyl-2-butanone & I & 12 & 7 & 9 & 2 \\
\hline 2-Methylpropanal & I & 12 & 7 & 9 & 2 \\
\hline \multirow[t]{2}{*}{ Pentanal } & I & 10 & 2 & 2 & 1 \\
\hline & II & 8 & 3 & 3 & 2 \\
\hline \multirow[t]{2}{*}{ 2-Pentanone } & I & 2 & 3 & 4 & 1 \\
\hline & II & 10 & 6 & 7 & 2 \\
\hline 2-Butanone & I & 5 & 2 & 2 & 1 \\
\hline \multirow[t]{2}{*}{ 3-Penten-2-one } & I & 9 & 5 & 5 & 1 \\
\hline & II & 11 & 6 & 7 & 2 \\
\hline Hexanal & I & 10 & 7 & 8 & 2 \\
\hline \multirow[t]{3}{*}{ 4-Heptanone } & I & 12 & 7 & 9 & 2 \\
\hline & II & 12 & 7 & 9 & 2 \\
\hline & III & 12 & 7 & 9 & 2 \\
\hline 2-Heptanone & I & 12 & 7 & 9 & 2 \\
\hline $\begin{array}{l}\text { 1,2,3- } \\
\text { Trimethylbenzene }\end{array}$ & I & 6 & 5 & 8 & 2 \\
\hline \multirow[t]{2}{*}{ Isoprene } & I & 8 & 2 & 3 & 0 \\
\hline & II & 5 & 5 & 5 & 1 \\
\hline Octanal & I & 12 & 7 & 9 & 2 \\
\hline
\end{tabular}


bottom of the filling chamber was kept at $30-31{ }^{\circ} \mathrm{C}$. At the onset of the experiment, $1 \mathrm{~mL}$ of urine sample was injected through the septum. Permeation of VOCs through the quartz sand was studied by the MCC/IMS analyses of the headspace samples taken approximately $1 \mathrm{~cm}$ above the sand layer in the direction of the central axis of the chamber. The time instants for drawing the samples were defined as follows: one sample was taken before the urine injection; the next ones were drawn every $10 \mathrm{~min}$ for $180 \mathrm{~min}$. For each size of grain, five experiments with urine of different volunteers were performed.

\section{Human subjects}

A cohort of 30 healthy normal volunteers ( 20 males, 10 females) was recruited. All subjects gave informed consent to participate and completed a questionnaire describing their food and drug intake, health status, smoking status, etc. None of volunteers had urological diseases. Demographic data for the volunteers are presented in Table 2.

\section{Results and discussion}

\section{Identification parameters}

In a recent study, a set of 33 potential volatile urine markers released from unmodified human urine at human body temperature using SPME-GC-MS was identified [3]. The markers within this group were omnipresent in human urine

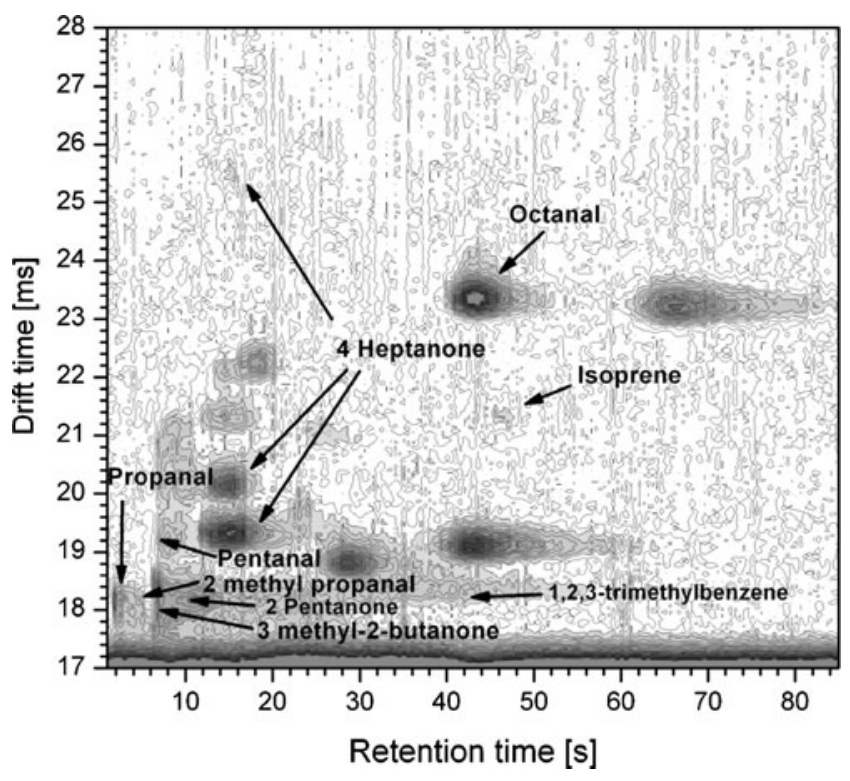

Fig. 2 An exemplary two-dimensional (contour) ion mobility spectrometry chromatogram of a human urine sample
Table 5 Filling chamber experimental conditions

\begin{tabular}{lllll}
\hline $\begin{array}{l}\text { Grain size } \\
(\mathrm{mm})\end{array}$ & No. & $\begin{array}{l}\text { Quartz mass } \\
(\mathrm{g})\end{array}$ & $\begin{array}{l}\text { Relative humidity } \\
(\%)\end{array}$ & $\begin{array}{l}\text { Temperature } \\
\left({ }^{\circ} \mathrm{C}\right)\end{array}$ \\
\hline $0.5-1$ & 1 & 500.0 & 28.9 & 23.9 \\
& 2 & 500.0 & 23.4 & 23.9 \\
& 3 & 500.6 & 26.3 & 24.0 \\
& 4 & 500.3 & 22.0 & 24.2 \\
& 5 & 500.0 & 25.3 & 24.2 \\
$1-2$ & 1 & 498.3 & 28.9 & 22.9 \\
& 2 & 503.6 & 22.3 & 23.4 \\
& 3 & 505.3 & 25.1 & 22.8 \\
& 4 & 500.0 & 23.8 & 23.0 \\
& 5 & 500.0 & 24.4 & 23.4 \\
$4-8$ & 1 & 503.9 & 20.8 & 22.6 \\
& 2 & 503.0 & 23.5 & 22.6 \\
& 3 & 501.3 & 26.9 & 22.8 \\
& 4 & 500.2 & 25.1 & 23.8 \\
\hline
\end{tabular}

with incidence higher than $80 \%$. Consequently, the present study focused on the identification of VOCs from this group. The identification parameters-retention times and reduced ion mobilities - are presented in Table 3. The identification parameters for allyisothiocyanate, isothiocyanocyclohexane and $\mathrm{N}$-methylpyrrole were not estimated owing to the lack of pure substances. Peaks for sulfur-containing compounds, namely dimethyl trisulfide, dimethyl sulfone, dimethyl sulfide and dimethyl disulfide, overlapped with the reactant ion peak. Consequently, these compounds could not be measured with the MCC/IMS system. However, under favourable conditions signals for these compounds could be extracted from the reactant ion peak using sophisticated algorithms. Furan, toluene and methanethiol were not detected. Finally, the original set of 33 potential urine markers was constrained to 23 compounds detectable with the IMS instrument. This set of VOCs served as a basic marker library for further investigations.

Detection of VOCs in the headspace of human urine

The compounds identified in the headspace of urine samples are presented in Table 4 together with their incidence. The compound was considered as detected if it was found at least two times out of three in the volunteer's urine. Urine of 30 volunteers was analysed: 21 morning urine samples and nine spontaneous urine samples. An exemplary two-dimensional IMS chromatogram of human's urine is shown in Fig. 2. Fourteen compounds were identified in the urine samples. Seven of them, namely 
Table 6 Compounds detected above the quartz sand layer together with their permeation times in minutes

\begin{tabular}{|c|c|c|c|c|c|c|c|c|c|c|c|c|c|c|c|}
\hline \multirow[t]{3}{*}{ Compound } & \multicolumn{15}{|c|}{ Grain size (mm) } \\
\hline & \multicolumn{5}{|c|}{$0.5-1$} & \multicolumn{5}{|c|}{$1-2$} & \multicolumn{5}{|c|}{$4-8$} \\
\hline & 1 & 2 & 3 & 4 & 5 & 1 & 2 & 3 & 4 & 5 & 1 & 2 & 3 & $4^{\mathrm{a}}$ & $5^{\mathrm{a}}$ \\
\hline Acetone & 40 & 40 & 40 & 40 & 40 & 30 & 30 & 30 & 30 & 30 & 20 & 20 & 20 & 70 & - \\
\hline Propanal & 40 & - & - & 40 & - & 30 & 30 & - & - & - & 30 & 40 & - & - & - \\
\hline 3-Methyl-2-butanone & 40 & 40 & 40 & 40 & 40 & 30 & 30 & 30 & 30 & 30 & 20 & 20 & 20 & 40 & 50 \\
\hline 2-Methylpropanal & 40 & 50 & 40 & 40 & 40 & 30 & 30 & 50 & 30 & - & 40 & - & - & 70 & 110 \\
\hline Hexanal & - & - & - & - & 40 & - & - & 30 & 30 & - & 30 & - & - & - & - \\
\hline 4-Heptanone & - & - & 130 & 110 & - & 70 & 70 & 70 & 60 & 60 & 60 & 60 & - & - & - \\
\hline 2-Heptanone & 130 & 90 & 80 & 90 & 40 & 80 & 90 & 80 & 70 & 70 & 50 & 50 & 80 & - & 110 \\
\hline 1,2,3-Trimethylbenzene & - & - & - & - & 170 & 50 & 50 & 40 & 40 & 40 & 30 & - & 50 & 160 & - \\
\hline \multirow[t]{2}{*}{ Isoprene } & 150 & - & - & 100 & 90 & - & 110 & 100 & 90 & 100 & 70 & 70 & 10 & 170 & - \\
\hline & 150 & - & - & 100 & 50 & 60 & 90 & 100 & 60 & 60 & 70 & 70 & 10 & 150 & - \\
\hline Octanal & 40 & 50 & 40 & 50 & 40 & 30 & 30 & 30 & 30 & 30 & 20 & 20 & 20 & 70 & 50 \\
\hline Pyrrole & - & - & - & - & - & 90 & 90 & 120 & 120 & 100 & 70 & 70 & 20 & - & - \\
\hline
\end{tabular}

${ }^{a}$ Spontaneous urine

acetone, propanal, 3-methyl-2-butanone, 2-methylpropanal, 4-heptanone, 2-heptanone and octanal, were found in all samples. A further two, hexanal and 2-pentanone, were detected in at least $80 \%$ of samples. No significant

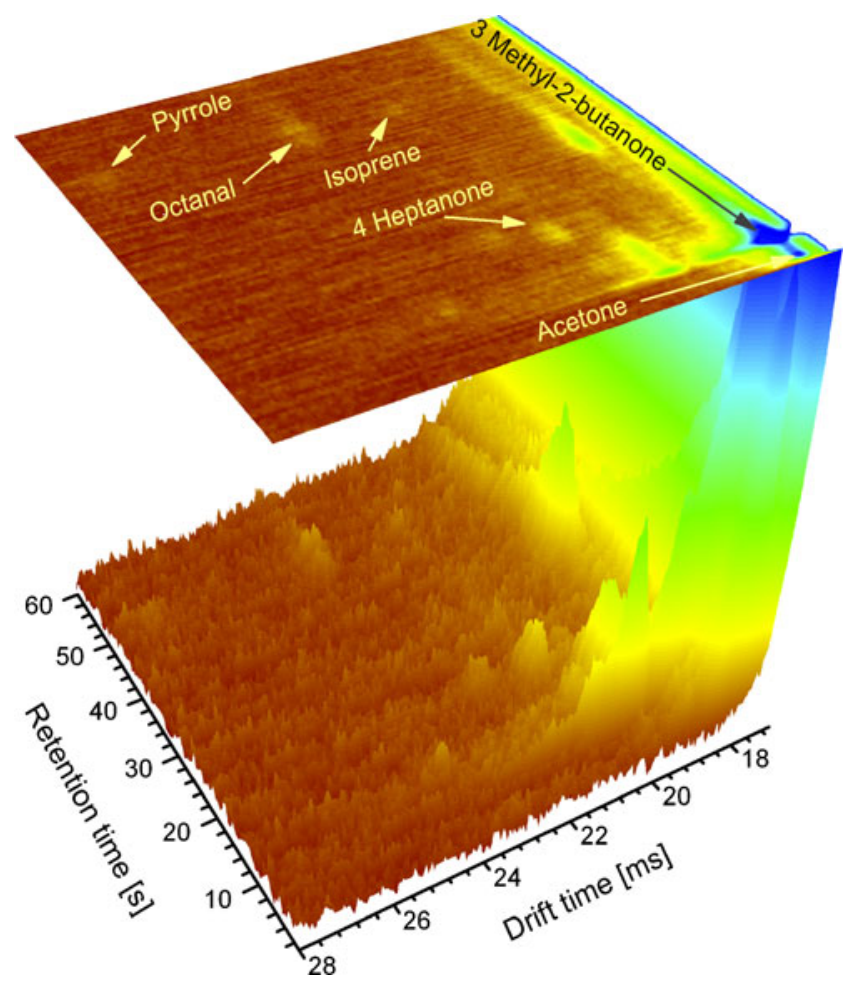

Fig. 3 Three-dimensional view of an ion mobility spectrometry spectrum showing volatile compounds of human urine sample which had passed through the layer of quartz sand (1-2 mm) differences between the morning urine and the spontaneous urine were observed.

Identification of compounds which pass through rubble

In this experiment, the quartz sand was exposed to VOCs released by unmodified human urine. The mass of quartz, the air temperature and the humidity during the experiments are summarized in Table 5. The VOCs detected in the chamber headspace are listed in Table 6 together with their permeation times. The experimental conditions were comparable. Relative humidity ranged from 20.8 to $28.9 \%$ (median 24.4\%), whereas ambient temperature was between 22.6 and $24.2{ }^{\circ} \mathrm{C}$ (median $23.4{ }^{\circ} \mathrm{C}$ ). Eleven compounds were identified in the air above the quartz layer during the 3-hlong experiments. Ketones were represented by acetone, 3methyl-2-butanone, 2-heptanone and 4-heptanone. Another well-represented class was aldehydes, also with four representatives: propanal, 2-methylpropanal, hexanal and octanal. Within the remaining species there was one aliphatic hydrocarbon (isoprene), one aromatic hydrocarbon (1,2,3trimethylbenzene) and one heterocyclic compound (pyrrole). Interestingly, pyrrole, which was not detected in the headspace of urine samples, was found to permeate through the quartz layer. This observation could be explained by a suppression of the pyrrole signal in the IMS owing to the presence of other VOCs with significantly higher proton affinities and a similar retention time. Two compounds, namely 3-methyl-2-butanone and octanal, were detected during all experiments, and a further two, acetone and 2heptanone, were detected in all samples but one. The shortest 
permeation times were noted for acetone, propanal, 3methyl-2-butanone and octanal. 4-Heptanon, which is among the most abundant VOCs present in human urine [4, 5], was detected only in nine experiments. In general, the permeation times increased with the decrease of the quartz grain size. However, it must be remembered that the urine samples used during the experiments originated from different volunteers and the initial VOC concentrations were different. An exemplary three-dimensional IMS chromatogram of a human urine sample taken over the quartz sand is presented in Fig. 3.

\section{Conclusion}

The present study aimed at evaluating the suitability of IMS for the detection of human urine during rescue operations after earthquakes or other disasters. For this purpose, IMS with a $\beta$-radiation source $\left({ }^{63} \mathrm{Ni}\right)$ and a $\mathrm{MCC}$ was applied. Twenty-three VOCs which are ubiquitous in human urine (according to previous SPME-GC-MS studies [3]) were detected with this technique. Fourteen compounds from this group were found in the headspace of human urine; however, only seven were omnipresent. Additionally, the IMS technique was used to study the permeation of urine vapour through the mimicking rubble quartz sand. Eleven compounds were found to permeate through the quartz layer. Within this group, four compounds, namely acetone, 3methyl-2-butanone, 2-heptanone and octanal, are of particular interest as they were commonly detected above the quartz layer exposed to the urine vapours and additionally exhibited the shortest permeation times. These compounds can be regarded as very promising markers of human urine.

Within this context, IMS can be considered as a potential technique suitable for the detection, localization and monitoring of VOCs evolved from human urine for the location of victims trapped in collapsed buildings. The main advantages of this technique are its good sensitivity (up to parts per trillion level), the short time of analysis and the potential for miniaturization. However, the trapped environment in collapsed buildings and especially in major disasters is extremely complicated and sometimes dominated by dust and smoke. Consequently, further investigation is necessary prior to selecting field chemical methods for the early location of trapped victims.

Acknowledgements This work was supported by the Foundation for Polish Sciences (FNP) Professor's Subsidy "Mistrz" and CEEPUS- II scholarship CII-PL-0004-05-0910-M-37834. The research leading to these results has received funding from the European Community's Seventh Framework Programme (FP7/2007-13) under grant agreement no. 217967 (SGL for USaR project, Second Generation Locator for Urban Search and Rescue Operations, http://www.sgl-eu.org). We appreciate funding from the Austrian Federal Ministry for Transport, Innovation and Technology (BMVIT/BMWA, project 818803, KIRAS). We greatly appreciate the generous support of the government of Vorarlberg and its governor Landeshauptmann Herbert Sausgruber.

Open Access This article is distributed under the terms of the Creative Commons Attribution Noncommercial License which permits any noncommercial use, distribution, and reproduction in any medium, provided the original author(s) and source are credited.

\section{References}

1. Ferworn A (2009) In: Helton WS (ed) Canine ergonomics: the science of working dogs. CRC, Boca Raton, pp 205-244

2. Wong J, Robinson C (2004) Urban search and rescue technology needs: identification of needs. Document number 207771. Federal Emergency Management Agency and the National Institute of Justice

3. Mochalski P, Krapf K, Schmid A, Ager C, Klieber M, Wiesenhofer H, Agapiou A, Statheropoulos M, Fuchs D, Kirsch A, Ellmerer E, Amann A (2010) Clin Chim Acta (submitted)

4. Statheropoulos M, Sianos E, Agapiou A, Georgiadou A, Pappa A, Tzamtzis N, Giotaki H, Papageorgiou C, Kolostoumbis D (2005) J Chromatogr B 822(1-2):112-117

5. Smith S, Burden H, Persad R, Whittington K, de Lacy Costello B, Ratcliffe NM, Probert CS (2008) J Breath Res 2(3):037022

6. Ruzsanyi V, Baumbach JI, Eiceman GA (2003) Int J Ion Mobil Spectrom 6:53-57

7. Hill HH, Hill CH, Asbury GR, Wu C, Matz LM, Ichiye T (2002) Int J Mass Spectrom 219:23-37

8. Ruzsanyi V, Baumbach JI, Sielemann S, Litterst P, Westhoff M, Freitag L (2005) J Chromatogr A 1084(1-2):145-151

9. Baumbach JI (2006) Anal Bioanal Chem 384(5):1059-1070

10. Westhoff M, Litterst P, Freitag L, Baumbach JI (2007) J Physiol Pharmacol 58(Suppl 5(Pt 2)):739-751

11. Ruzsanyi V, Baumbach JI (2005) Int J Ion Mobil Spectrom 8:5-7

12. Bödeker B, Vautz W, Baumach JI (2008) Int J Ion Mobil Spectrom 11:89-93

13. Karpas Z, Tilman B, Gdalevsky R, Lorber A (2002) Anal Chim Acta 463(2):155-163

14. Bota GM, Harrington PB (2006) Talanta 68(3):629-635

15. Matz LM, Hill HH (2001) Anal Chem 73(8):1664-1669

16. Lawrence AH (1989) Anal Chem 61(4):343-349

17. Eiceman GA, Karpas Z (2005) Ion mobility spectrometry. CRC, Boca Raton

18. Xie Z, Sieleman S, Schmidt H, Li F, Baumbach JI (2002) Anal Bioanal Chem 372:606-610

19. Xie Z, Ruzsanyi V, Sieleman S, Schmidt H, Baumbach JI (2001) Int J Ion Mobil Spectrom 2:88-91

20. Perl T, Carstens E, Hirn A, Quintel M, Vautz W, Nolte J, Junger M (2009) Br J Anaesth 103(6):822-827

21. Vautz W, Zimmermann D, Hartmann M, Baumbach JI, Nolte J, Jung J (2006) Food Addit Contam 23(11):1064-1073

22. Li F, Xie Z, Schmidt H, Sielemann S, Baumbach JI (2002) Spectrochim Acta B 57:1563-1574

23. Lide DR (ed) (2010) CRC handbook of chemistry and physics, 90th edn. Boca Raton, CRC 